\title{
QUINE'S POOR TOM
}

\section{TRISTAN GRØTVEDT HAZE}

The University of Sydney

Original scientific article - Received: 04/01/2019 Accepted: 28/01/2019

\begin{abstract}
Section 31 of Quine's Word and Object contains an eyebrow-raising argument, purporting to show that if an agent, Tom, believes one truth and one falsity and has some basic logical acumen, and if belief contexts are always transparent, then Tom believes everything. Over the decades this argument has been debated inconclusively. In this paper I clarify the situation and show that the trouble stems from bad presentation on Quine's part.
\end{abstract}

Keywords: belief contexts, referential transparency, opacity, Quine, perspicuity

\section{Introduction}

Section 31 of Quine's Word and Object contains an eyebrow-raising argument. The argument purports to show that if an agent, Tom, believes one truth and one falsity and has some basic logical acumen, and if belief contexts are always transparent (what this comes to is explained at the beginning of Section 1, but the basic idea will already be familiar to many readers), then Tom believes everything. Quine's larger aim with this argument was to show that we cannot always treat belief contexts as transparent.

Philosophers have debated this argument over the decades, inconclusively. A perceptive but not fully adequate objection appeared in Sleigh (1966). Widerker (1977) and Sayward (2007) levelled criticisms at Sleigh's objection which have not been properly assessed. Thus, the overall 
impression one may get from the literature on this argument is that it was questioned at one time (by Sleigh) but then vindicated (by Widerker and Sayward). This impression is mistaken. My aim in this paper is to sort this out and attain a better view of the status of Quine's provocative argument and what might be objectionable about it.

To anticipate, the view I will propose regarding this argument is as follows. Quine here had all the makings of a perspicuous argument which does indeed lead to the desired conclusion that belief contexts cannot always be treated as transparent. But he instead presented a provocative argument for a very striking conclusion, the sort of conclusion that makes one think "How could that be?", out of which then falls the desired bigger-picture conclusion that belief contexts cannot always be treated as transparent.

The plan of this paper is as follows. In Section 1 I present Quine's argument. In Section 2 I present Sleigh's objection. In Section 3 I consider Sayward's objection to Sleigh's objection and argue that it fails. In Section 4 I consider Widerker's objection, granting him a point against Sleigh but suggesting that his main point is suspect. I end in Section 5 by showing how Quine could have argued. Widerker will turn out to be right in his basic idea that Quine's argument can be modified to yield a better argument, although the modification is not the one proposed by Widerker. This opens the way to a deeper understanding of what is wrong with Quine's argument.

\section{Quine's Argument}

Before we proceed to Quine's argument, let us rehearse Quine's definition of referential transparency. (Familiar readers can skip this and the following paragraph.) Quine defines transparency in terms of "modes of containment $\ldots$ of singular terms or sentences in singular terms or sentences". Definite descriptions count here as singular terms. For Quine, a mode of containment $\varphi$ is referentially transparent iff, "whenever an occurrence of a singular term $t$ is purely referential in a term or sentence $\psi(t)$, it is purely referential also in the containing term or sentence $\varphi(\psi(t))$ " (Quine 1960,144). For a singular term $t$ to be purely referential in a term or sentence is for it to occupy a purely referential position there. Quine's criterion for a position's being purely referential is that the position "must be subject to the substitutivity of identity" (Quine 1960, 142).

To explain with an example: the occurrence of "John" in the statement "John is happy" is purely referential, since substituting another term which 
refers to the same person could not turn this statement from true to false or from false to true. Now consider the mode of containment "It is true that ...". This mode of containment seems to be referentially transparent (or just "transparent" for short), since "John" in "It is true that John is happy" seems purely referential just as in "John is happy". By contrast, it is doubtful whether a mode of containment such as "Lois Lane believes that ..." may always be regarded as transparent. After all, we may happily grant that Lois Lane believes that Superman can fly but deny, or at least hesitate to affirm, that Lois Lane believes that Clark Kent can fly. Quine here wants to vindicate this doubt, by arguing that such modes of containment - belief contexts - cannot always be regarded as transparent.

Now, Quine assumes that Tom believes the true sentence "Cicero denounced Catiline" and the false sentence "Tully did not denounce Catiline". That these sentences are (in a sense) contradictories, and that they are about the same person, is not essential for Quine's argument. These things were needed for earlier, separate arguments in chapter IV of Word and Object.

Here is the argument:

Where " $p$ " represents a sentence, let us write " $\delta p$ " (following Kronecker) as short for the description:

the number $x$ such that $((x=1)$ and $p)$ or $((x=0)$ and not $p)$.

We may suppose that poor Tom, whatever his limitations regarding Latin literature and local philanthropies, is enough of a logician to believe a sentence of the form " $\delta p=1$ " when and only when he believes the sentence represented by " $p$ ". But then we can argue from the transparency of belief that he believes everything. For, by the hypothesis already before us,

(3) Tom believes that $\delta($ Cicero denounced Catiline $)=1$.

But, whenever " $p$ " represents a true sentence,

$\delta p=\delta($ Cicero denounced Catiline $)$.

But then, by (3) and the transparency of belief,

Tom believes that $\delta p=1$, 
from which it follows, by the hypothesis about Tom's logical acumen, that

(4) Tom believes that $p$.

But " $p$ " represented any true sentence. Repeating the argument using the falsehood "Tully did not denounce Catiline" instead of the truth "Cicero denounced Catiline", we establish (4) also where " $p$ " represents any falsehood. Tom ends up believing everything. (Quine 1960, 148-149)

\section{Sleigh's Objection}

Sleigh's objection to the above argument takes the form of a dilemma concerning the interpretation of Quine's hypothesis about Tom's logical acumen. In Sleigh's reconstruction of Quine's argument, the hypothesis runs as follows:

(AmbigAcumen) Tom believes that $\delta p=1$ if and only if Tom believes $p$. (Sleigh 1966, 92)

(The label is my own - Sleigh dubs it "(4)". I do not know if Sleigh had a reason for omitting "that" before the " $p$ " at the end or if it was just a slip.)

Sleigh notes that, intuitively, (AmbigAcumen) is ambiguous between a transparent and an opaque reading. The crux of his objection is contained in the following passage ${ }^{1}$ :

But [(AmbigAcumen)] asserts the relevant acumen of Tom only if " $\delta p$ " in [(AmbigAcumen)] is taken opaquely, in which case the argument is simply invalid. Obviously, [a transparent disambiguation of (AmbigAcumen)] does not express the idea of Tom's acumen. ${ }^{2}$ (Sleigh 1966, 93)

In other words, either we understand (AmbigAcumen) transparently, in which case it is obviously not something which would hold of Tom in

\footnotetext{
${ }^{1}$ The square brackets contain replacements, more convenient for present purposes, for Sleigh's labels.

${ }^{2}$ You may notice that Sleigh talks of a referring term, rather than a context (or "mode of containment"), as being opaque, and locates the ambiguity there. Locating the ambiguity in the mode of containment "believes (...)" arguably makes more sense, and certainly fits better with Quine's official terminology - but that is a minor quibble which does not matter for our purposes.
} 
virtue of any logical acumen he may have, or we understand it opaquely, in which case it cannot be used in Quine's argument.

A further point Sleigh could have made here is that, unlike (AmbigAcumen) as reformulated by Sleigh using that-clauses, Quine's original formulation of his hypothesis about poor Tom's acumen is put in terms of sentences. (Recall, Quine writes "We may suppose that poor Tom, whatever his limitations regarding Latin literature and local philanthropies, is enough of a logician to believe a sentence of the form " $\delta p=1$ " when and only when he believes the sentence represented by ' $p$ "'.) This all but ensures an opaque reading.

\section{Sayward's Objection to Sleigh's Objection}

Sayward objects to Sleigh's objection on the grounds that Sleigh has not argued for the claim that (AmbigAcumen) read transparently does not express the idea of Tom's acumen. When discussing Quine's argument, Sayward uses a construction involving sets in place of Quine's one involving numbers, but the essential thing is that, like Sleigh, he uses notation to disambiguate (AmbigAcumen) (writing "BELIEVES" for the transparent reading and "believes" for the opaque). We will abstract from the distracting details by simply using the names "(TransparentAcumen)" and "(OpaqueAcumen)".

What Quine supposed about poor Tom's logical acumen was, according to Sleigh, this:

$[($ OpaqueAcumen $)]$

not this

[(TransparentAcumen)]

But apart from that point - a point of how to interpret the biconditionals which occur in the argument as premises-Sleigh offers no objection.

Now, the interesting question is not whether the type of logical acumen of which Quine spoke is expressed by [(TransparentAcumen)] but whether there is any logical acumen fairly broadly shared among us which is expressed by that sentence. (...)

So if Sleigh's point is to carry much weight it must take the form of a claim that no logical acumen, or at least none at all widely shared, 
is expressed by [(TransparentAcumen)]. But so far as I can see that simply goes unargued in his paper. Indeed, so far as I can see the paper contains no argument that the logical acumen to which Quine referred is not expressed by [(TransparentAcumen)]. It is simply and baldly asserted. (Sayward 2007, 57-58)

This objection can be convincingly rebutted. Firstly, it gets the dialectic wrong. Quine, for his argument to be plausible, needs his hypothesis about Tom's logical acumen to be about some genuine, plausible kind of logical acumen. It is perfectly fair to point out that this only seems to be so if we take the hypothesis opaquely, in which case it doesn't support the argument. That is already a good objection, without a further argument that it is not the case that (TransparentAcumen) does express logical acumen after all.

But there is a much stronger response to be made to Sayward's objection to Sleigh's objection: Sleigh does give an argument that no logical acumen is expressed by (TransparentAcumen)! Sayward's claim that he does not do so is a sheer mistake. It is true that Sleigh prefaces his claim that no logical acumen is expressed by (TransparentAcumen) with "Obviously", but he does not leave the matter there. He goes on to argue for what he has claimed is obviously the case. The argument comes at the end of his note and runs as follows (I have, for ease of reading, removed the subscript notation which he applies to singular terms to disambiguate between transparent and opaque, and simply put bracketed specifications of the intended reading next to "believes" instead):

Obviously, (4') does not express the idea of Tom's acumen. Consider:

(9) Tom believes [transparent] that $[\delta p]=1$.

and

(10) Tom believes [opaque] that $[2-1]=1$.

Given (10), (9) is true provided the sentence represented by " $p$ " is true. But we cannot infer from this that Tom believes the sentence represented by " $p$ " even if every singular term in " $p$ " is taken transparently and even if Tom is overflowing with logical acumen. (Sleigh 1966, 93)

Clearly, this is an argument - so Sayward is just wrong in saying that Sleigh doesn't offer one. It seems to be a perfectly good argument, too- 
although I think it was unnecessary to make "believes" in (10) opaque, and as will become clear, this makes Sleigh more vulnerable to Widerker's criticism, which we will consider in the next section.

Finally, in case there is any remaining doubt, here is another argument that (TransparentAcumen) does not express any sort of logical acumen. We can express (TransparentAcumen) as follows:

(TransparentAcumen) Tom believes [transparent] that $\delta p=1$ when and only when he believes [transparent] that $p$.

Now, let us plug in some truth for " $p$ " which not everyone with logical acumen knows - say, "Quine was born in 1908":

Tom believes [transparent] that $\delta($ Quine was born in 1908) $=1$ when and only when he believes [transparent] that Quine was born in 1908.

Now, substituting " 1 " for the co-extensive " $\delta$ (Quine was born in 1908)", we get

Tom believes [transparent] that $1=1$ when and only when he believes [transparent] that Quine was born in 1908.

This is plainly not something we should require of a reasoner. Using "of" to induce a transparent reading, so that the point reads more intuitively: a reasoner may fail to believe, of Quine, that he was born in 1908. They may not have any beliefs about Quine at all. Obviously, they should not in that case - by the "only when", which is essential to Quine's argument - fail to believe, of 1 , that it is equal to 1 . But we obtained this wrong result just by substituting co-extensive terms in an instance of (TransparentAcumen). Therefore (TransparentAcumen) does not express any sort of logical acumen. Rather, it seems like something we definitely shouldn't conform to. We have now completely diffused Sayward's objection to Sleigh's objection.

\section{Widerker's Objection to Sleigh's Objection}

At the heart of Widerker's objection to Sleigh's objection is the observation that Quine is arguing, not that the assumption that there are transparent belief contexts leads to absurdity, but that the assumption that belief contexts are invariably transparent leads to absurdity. It is hard to deny that Widerker is right about this interpretative point. Widerker quotes Quine's summary of the lesson of his argument: 
Thus in declaring belief invariably transparent ... we would let in too much. (Quine 1960, 135)

And draws attention to the last two sentences of Sleigh's article:

That the transparent sense of belief is odd is beyond doubt. That it is as odd as Quine suggests does seem doubtful. (Sleigh 1966, 93)

Widerker suggests that

[Sleigh's] criticism of Quine stems from the fact that he interprets Quine's argument as being directed against the intelligibility of the transparent sense of belief. However that's not the case. Quine uses his argument only to show that the transparent sense can't be the only sense appropriate for the analysis of belief contexts. In other words, Quine is not arguing against the transparent sense of belief as such, but against the attempt to treat all belief contexts transparently. (Widerker 1977, 357)

What I will now argue is that, while it is a fair point that Sleigh does seem to interpret Quine's argument as Widerker says he does, and that this isn't correct, the core of Sleigh's objection still applies. ${ }^{3}$

Unlike Sayward, Widerker allows that (TransparentAcumen) does not actually capture any logical acumen. This can be seen from this passage from a footnote occurring in Widerker's diagnosis of Sleigh's misinterpretation:

If Quine would be arguing against the transparent sense of belief alone, then indeed Sleigh's charge would be correct because in such a case Quine would be arguing from a premise (that about Tom's logical acumen) which is not captured adequately by the transparent sense of belief. (Widerker 1977, 358, fn. 7)

His criticism is this: once we recognize that Quine is arguing on the assumption that all belief contexts are transparent, then the needed (TransparentAcumen) follows from (AmbigAcumen), allowing Quine's argument - supposing it is not quite right, or unfortunately enthymematic, as it stands - to be easily patched up:

\footnotetext{
${ }^{3}$ If I am right, Widerker's claim that Sleigh's objection stems from his misinterpretation is also doubtful - though this causal question about Sleigh's thought process is not important for my purposes in this paper.
} 
It is not difficult, however, to meet this objection. We may certainly agree with Sleigh that a valid derivation of [the conclusion that Tom believes any arbitrary truth $\left.^{4}\right]$ rests on [(TransparentAcumen)] and that it can't be identified with [(AmbigAcumen)], but nevertheless [(TransparentAcumen)] follows from [(AmbigAcumen)] given the assumption that all belief contexts are transparent. (Widerker 1977, 356)

One problem with this is that the acumen hypothesis in Quine's original argument is not (AmbigAcumen), but is put in terms of belief in sentences, which, as I noted at the end of Section 2, all but ensures an opaque reading. But there is, I think, a deeper problem with this defense of Quine's argument. The defense trades on a subtly objectionable handling of the idea of what follows from an ambiguous statement. I will try to bring this out with an analogy. Consider the ambiguity of "bank" in English, whereby it may mean either a money bank or a river bank. Now consider the following argument:

Suppose John has some money, and suppose that he has enough civic common sense to put it in the bank. Now, suppose that "bank" in English always meant a river bank. In that case John's money is in a river bank.

I submit that there is something objectionable about this argument, and that it is objectionable in a way analogous to Quine's argument. Furthermore, suppose we discharge the assumptions and outline the putative lesson of the argument as follows:

If John has some money and a certain basic kind of civic common sense, and if "bank" always means a river bank, then John's money is in a river bank.

This is an objectionable statement, objectionable in a way analogous to the putative lesson of Quine's argument.

Now let us consider an objection to the bank argument analogous to Sleigh's objection to Quine's argument:

\footnotetext{
${ }^{4}$ Widerker notes that his reconstructed argument can be repeated with any arbitrary falsity. Thus putting two iterations of the argument together yields the conclusion that Tom believes everything.
} 
For the assumption about John's civic common sense to be about something which plausibly does constitute civic common sense, "bank" needs to be given its money bank reading, but for it to lead to the conclusion that John's money is in a river bank, "bank" needs to be given its river bank reading.

I think this objection, like Sleigh's, is quite compelling. Now let us consider a criticism of this Sleigh-style objection to the bank argument analogous to Widerker's criticism of Sleigh's objection:

It is not difficult to meet this objection. We may certainly agree that the conclusion that John's money is in a river bank rests on the riverbank reading of the ambiguous claim that John's money is in a bank, but it does follow from that ambiguous claim given the assumption that "bank" always means a river bank.

This seems dubious. If a claim is ambiguous between two readings, some things will follow from it on one reading, and some things will follow from it on another. You can't treat it as a thing which can be combined with an assumption ("bank" always means a river bank), whose truth would make one of the readings impossible, to yield the consequences of the other reading.

But what am I saying? Maybe you can so treat an ambiguous claim. (After all, what would stop you?) Perhaps the point is that you shouldn't, for if you do you get dubious results which may impress some but which make others - such as Sleigh and myself - want to object.

At this point it becomes important to note, something which Sleigh did not, that in both the belief case and the bank case, we do have before us all that we need to argue for the desired linguistic conclusions. All this tussling over Quine's argument really has no bearing on whether or not you can show that not all belief contexts are transparent; the fundamental problem with Quine's argument is more of a matter of presentation than it may seem. Let me try to make this clearer by showing how Quine could have argued.

\section{How Quine Could Have Argued}

Instead of trading on an ambiguity, by baiting us with the plausible reading of an ambiguous assumption and then switching to its implausible reading in order to deliver a striking, paradoxical conclusion, Quine could have argued as follows: 
Surely,

(1) There is a reading of (AmbigAcumen) which does express some logical acumen.

Now, suppose for the sake of argument that

(2) All belief contexts are transparent.

In that case,(AmbigAcumen) would unambiguously amount to (TransparentAcumen), and if Tom conformed to that, and if he believed one truth and one falsity, he would believe everything (as Quine's manipulations with the " $\delta$ " device show). But this is absurd, and so, by (1), (2) cannot be the case. Q.E.D.

Presenting things perspicuously, we can see that the real engine of Quine's argument - the series of manipulations with the " $\delta$ " device - is actually just another argument that (TransparentAcumen) doesn't express any sort of logical acumen. I.e., that which Sayward, who was trying to defend Quine's argument, mistakenly claimed that Sleigh had not provided, and which I provided another instance of for good measure.

\section{REFERENCES}

Quine, W. V. 1960. Word and Object. Cambridge, MA.: The MIT Press.

Sayward, C. 2007. Quine and his Critics on Truth-Functionality and Extensionality. Logic and Logical Philosophy 16: 45-63.

Sleigh, R. C. Jr. 1966. A note on an argument of Quine's. Philosophical Studies 17: 91-93.

Widerker, D. 1977. Epistemic opacity again. Philosophical Studies 32: 355-358. 
Tristan Grøtvedt Haze 